Arab Univ. J. Agric. Sci., Ain Shams Univ., Cairo, Egypt 28(3), 871-884, 2020

Website: http://ajs.journals.ekb.eg

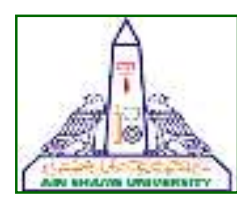

\title{
POPULATION STRUCTURE AND GENOME-WIDE ASSOCIATION ANALYSIS FOR SALINITY TOLERANCE IN BREAD WHEAT USING SNP, SSR AND SCOT MARKER ASSAYS
}

\author{
Alsamman A.M. ${ }^{1 *}$, Ibrahim S.D. ${ }^{1}$, Rashed M.A. ${ }^{2}$, Atta A.H.A. ${ }^{2}$, \\ Ahmed M.S. ${ }^{1 \& 3}$ and Hamwieh A. ${ }^{3}$
}

1- Agricultural Genetic Engineering Research Institute, PO Box 12619, Giza, Egypt

2- Genetics Dept., Fac. of Agric., Ain Shams Univ., P.O. Box 68, Hadayek Shoubra 11241, Cairo, Egypt

3- International Center for Agricultural Research in the Dry Areas (ICARDA), PO Box 2416, Cairo, Egypt

*Corresponding author: smahmoud@ageri.sci.eg

Received 30 August, 2020

Accepted 25 September, 2020

\section{ABSTRACT}

Wheat is an essential staple food in the developing world, where demand is projected to grow exponentially in the future; simultaneously, climate changes are projected to reduce supply in the near future. One of the main consequences of climate change is salinity, which negatively impacts the world's cultivated area and therefore affects the global wheat production. Our objectives are to study the population structure of several Egyptian and international wheat accessions and to identify the genetic factors controlling the salinity stress response of bread wheat. In addition, we have attempt to identify genes that control some important agronomic parameters of wheat under salinity stress were identified. The wheat germplasm panel consisted of 70 accessions obtained from Egypt, Syria and Iran. The assessment of salinity tolerance was conducted over the years of 2018 and 2019 in the field and in the greenhouse. The genome association analysis (GWAS) and population structure analysis was conducted using six SCoT, five SSR and 93 SNP markers. Analysis of the population structure using allele frequency and phylogenetic analysis indicated that the studied wheat accessions were belong to four population groups. Where, for the most portion, Egyptian, Syrian and Iranian accessions are clustered depending on their country of origin. The GWAS analysis revealed 13 SNP markers that were significantly associated with morpho-agronomic wheat traits during salinity stress. These markers were closely related to genes that are known to have a direct link to wheat response to salinity stress such as CYP709B2, MDIS2, STAYGREEN, PIP5K9, and MSSP2 genes. This study revealed the genetic structure of adapted and imported wheat accessions, which could be used to select potential wheat accessions for local breeding programs. In addition, the SNP genotyping assay is a very potential technology that could be efficiently applied to detect genes that control bread wheat response to salinity stress.

Keywords: Wheat, Salinity, SNP genotyping, SSR, SCOT, GWAS

\section{INTRODUCTION}

The domestication of wheat ( Triticum sp.) began in the Fertile Crescent around 10,000 years ago (Faris, 2014) . It is the most essential staple food of about $36 \%$ of humans, where $55 \%$ of the world's population relies on wheat for about $20 \%$ intake of food calories (Aryan et al 2018). In the developing world, wheat demand is projected to grow by $60 \%$ by 2050; at the same time, climate change-induced temperature rises are predicted to decrease wheat supply (Alexandratos and Bruinsma, 2012). In addition, global wheat production will be exponentially affected by major biotic and abiotic stress, including drought, salinity and plant diseases. Salinity will have a negative impact on $6.5 \%$ of the total land, which translates into 8 million $\mathrm{km}^{2}$ of cultivable land ("FAOSTAT," 2018). 
As a response to environmental changes, the rapid growth of genotypic and phenotypic analysis technologies has enabled the examining of the genomic content of many economic crops (Aliyu et al 2011; Awan, 2019; Girish and Dubey, 2018). Such methods would provide efficient information that could be used to improve the response of these crops to dramatic changes in the environment and therefore to maintain global cereal production. The yield of wheat grains is a dynamic trait based on multiple genes interacting with each other and the environment (Wu et al 2012). In this regard, molecular marker technologies have proved their value in the detection and tagging of several genetic loci associated with crop tolerance to biotic and abiotic stresses (Hassan et al 2020; Nahas et al 2020). For instance, simple sequence repeat (SSR) marker technology was successfully used to evaluate the diversity and genetic structure of wheat cultivars, corresponding to their origin, productivity and ability to perform effectively in different environments (Abbasabad et al 2017; Würschum et al 2013). Aditionally, SSR markers, which chracterized bymulti-allelism, high reproducibility, co-dominance, and genomic abundance and transferability have support its usefulness in identifying genetic loci associated with the ability of wheat to tolerate drought, salinity and several diseases (Qadir et al 2014; Turki et al 2015). Other marker assays such as Start Codon-Targeted (SCoT) were developed on the basis of a short standard area flanking the start codon of ATG in plant genome. SCoT markers could be more effective than other random marker technologies, particularly due to high annealing temperatures and longer PCR primers (Collard and Mackill, 2009). Various molecular studies have used the SCoT marker to study different plant species including wheat (Etminan et al 2016), olive (Alsamman et al 2017), maize (Vivod'ík et al 2017), and tomato (Abdein et al 2018).

Owing to its evolutionary relationship, genome abundance, applicability for population structure assessment, and agronomic traits association, single nucleotide polymorphism (SNP) markers have acquired remarkable value in crop genetics (Rafalski, 2002). Genome-wide association (GWAS) analysis through SNP genotyping technology has a major influence on the detection of genetic loci correlated with quantitative and complex features (Zaimah, 2019). This methods have been used to study and analyze the genetic architecture for crop resilience and grain production in wheat under salinity (Hussain et al 2017), drought (Ballesta et al 2020) and disease stresses
(Perez-Lara et al 2017). Moreover, recent bioinformatics techniques provide a golden opportunity to filter trait-associated SNPs, depending on their impact on gene activity.

The study of the response of economic crops, such as wheat, to environmental changes, is therefore vital for future genetic improvement (Nassar et al 2018). Unfortunately, the large genome of wheat limits such studies, requiring advanced biological data analysis techniques. Our objective is to study the population structure of several Egyptian, Syrain and Iranian wheat accessions and to identify the genetic factors controlling the salinity stress response of bread wheat. In addition, we have attempt to identify genes that control some important agronomic parameters of wheat under salinity stress.

\section{METHODOLOGY}

\section{Plant Material}

The studied germplasm panel consisted of 70 bread wheat accessions obtained from Egypt, Syria and Iran. This subset was chosen from the International Center for Agricultural Research in the Dry Areas (ICARDA) and Agricultural Research Center gene banks, Giza, Egypt.

\section{Salinity tolerance phenotyping}

Forty-four foreign international accessions (Syrian and Iranian genotypes) were chosen using Focused Identification of Germplasm Strategy (FIGS) method for the assessment of salinity tolerance over the years 2018 and 2019. Evaluations were performed in the field (Arish province, Sinai, Egypt) and in a greenhouse (Agricultural Research Center - ARC, Giza, Egypt) using a hydroponic system. The evaluation was done in three replications using the Alpha Lattice design. In the field, an irrigation system of dripping water was installed and the field was irrigated one time every two weeks. A sample of soil was air-dried and used as a soil solution for $\mathrm{pH}$ and salt concentration analysis to evaluate the salt content in the field soil (Sparks et al 2020). The concentration of salt in the field at depths of 30 and $60 \mathrm{~cm}$ was 344, 904 ppm, respectively, and 848 ppm at depths of more than $60 \mathrm{~cm}$. The morphoagronomic traits of plant hight $(\mathrm{PH})$, number of tillers (NT), Days to $50 \%$ of flowering (DF), number of spikes (NS), spike height (SH), and number of spikelets (NSL) were measured. In the greenhouse, three seeds of each accession were germinated in 
small pots containing a mixture of perlite $(60 \%)$ and peat moss $(40 \%)$. The plantlets were transferred after two weeks to hydroponic tanks. Electrical conductivity (EC) meter (Hanna HI8733) was used to measure the salt concentration in the greenhouse, which was calibrated at $5,844 \mathrm{ppm}(\mathrm{pH}$ 8 ). The plant salinity tolerance rate (STR) was measured in the range of 1 (normal) to 5 (dead). Throughout the trial, plant performances were scored three times, at an interval of two weeks.

\section{DNA extraction and analysis of molecular} markers

DNA was extracted from young leaves of four to six week old seedlings using the cetyl trim ethyl ammonium bromide (CTAB) method (Rogers and Bendich, 1989). Through PCR-based assays, five SSR and six SCoT primers were applied (Table 1). The reactions of SSR and SCOT PCR analyses were performed in a $15 \mu \mathrm{l}$ volume of reaction contained a $5 \mathrm{ng}$ of DNA, a $10 \mathrm{pmol}$ of each primer, a $2 \mathrm{mM}$ of dNTPs, a $25 \mathrm{mM}$ of $\mathrm{MgCl}_{2}$, a $0.1 \mathrm{U}$ of Taq DNA polymerase, and 10X PCR buffer. For 35 cycles, the SSR PCR program included $95^{\circ} \mathrm{C}(5$ $\min ), 95^{\circ} \mathrm{C}(15 \mathrm{sec}), 55^{\circ} \mathrm{C}(15 \mathrm{sec})$ and $72^{\circ} \mathrm{C}(30$ $\mathrm{sec})$. Thereafter a final extension step was applied at $72^{\circ} \mathrm{C}$ for $7 \mathrm{~min}$. The SCOT PCR program and reaction content were conducted as reported by Ibrahim et al (2016). Ethidium bromide stained agarose gel (8\%) was used to distinguish among PCR fragments. Gel images were documented using the Gel Doc XR system (Bio-Rad, Hercules, CA, USA). Fragments of PCR products were counted as present (1) or absent (0) for all tested wheat accessions.

The SNP panel of DarT® company (Triticarte Pty. Ltd. Australia) was applied to the forty four 44 wheat accessions. The DNA was sent to marker genotyping as a supplier for profit-oriented service. A 93 SNP marker loci (Table 2) were used for GWAS analysis. The BLAST software (Altschul et al 1997) was used to locate SNP markers on wheat chromosomes (Wheat Consortium, 2014).

\section{Statistical and genetic analyses}

The phylogenetic and diversity analysis was conducted using Dice's similarity matrix coefficients using Dendro-UPGMA online tool (http:// genomes.urv.es/UPGMA/). The online iTOL software was used to construct phylogenetic trees that show evolutionary relationships among tested wheat accessions. The GWAS analysis of the SNP markers and morpho-agronomic traits of wheat was conducted using GAPIT software (R Package) (Lipka et al 2012). The population genetic structure of the tested wheat accessions was studied by STRUCTURE (https://web.stanford.edu) and strplot2 software (http://omicsspeaks.com/strplot2/) using 5000 burn-in and MCMC iterations. The Circos software package was used to illustrate the different results of GWAS on the wheat genome (Krzywinski et al 2009).

\section{RESULTS AND DISCUSSION}

\section{Genetic polymorphism of the PCR markers}

Studying the genetic diversity of local and international accessions of wheat could benefit local breeding programs by enriching their genetic resources with more adaptive and stable accessions. PCR-based techniques such as SCoT and SSR could provide different but complementary information regarding wheatevolutionary adaptation to environment. In this regard, a total number of 61 PCR-bands were revealed using SSR and SCoT primers, where SCoT assay provided a higher number of bands (46 bands) compared to SSR assay (15 bands) (Table 3 and Fig. 1). The maximum number of bands was obtained from SCoT-05 were 10 bands. Additionally, the total number of polymorphic bands was 48 bands, where SCoT-10, and SCoT-01 revealed the maximum number of polymorphic bands (8 bands). The PCR primers of SCOT-02, and SSR-01 revealed the maximum percentage of polymorphism (100\%) (Table 3 and Fig. 1). On the other hand, among the 91 SNP primers used for SNP genotyping of wheat, only 17 makers were monomorphic.

Etminan et al (2016) used six SCoT primer to study the genetic diversity of several durum genotypes, where they obtained 54 PCR bands with polymorphism percentage of a $100 \%$. SCoT assay was used to assess the genetic variability of some Egyptian wheat cultivars, where 32 bands with a $59 \%$ of polymorphism using six SCOT primers were detected (Abdel-Lateif et al 2018). In addition, 14 ScoT primers were used to study the population structure of 17 durum wheat genotypes, generating a total of 118 bands with a polymorphism of $83.24 \%$ (Heidari et al 2017). SCoT was used to identify the allelic variation among multiple olive genotypes, moderate ability of SCoT markers to detect genetic variation compared to other molecular assays was recorded (Alsamman et al 2017). The genetic diversity of 480 bread wheat accessions, chosen from 
Table 1. Sequences and code names of SCoT and SSR primers used for the PCR-based genotyping of wheat genotypes.

\begin{tabular}{|c|c|c|}
\hline Name & Forward primer & Reverse primer \\
\hline SSR-1 & GACAGCACCTTGCCCTTTG & CATCGGCAACATGCTCATC \\
SSR-2 & AAAGAGGTCTGCCGCTAACA & TATACGGTTTTGTGAGGGGG \\
SSR-3 & TTCAATTCAGTCTTGGCTTGG & CTGCAGGAAAAAAAGTACACCC \\
SSR-4 & GATGAGCGACACCTAGCCTC & GGGGTCCGAGTCCACAAC \\
SSR-5 & CTGCAGGCCATGATGATG & ACCGTGGGTGTTGTGAGC \\
SCoT-1 & CGACATGGCGACCACGC & - \\
SCOT-2 & ACCATGGCTACCACCGGC & - \\
SCOT-3 & CGACATGGCGACCCACA & - \\
SCoT-4 & ACCATGGCTACCACCGCA & - \\
SCoT-5 & CAATGGCTACCACTAGCG & - \\
SCoT-10 & ACAATGGCTACCACCAGC & - \\
\hline
\end{tabular}

SCOT-10

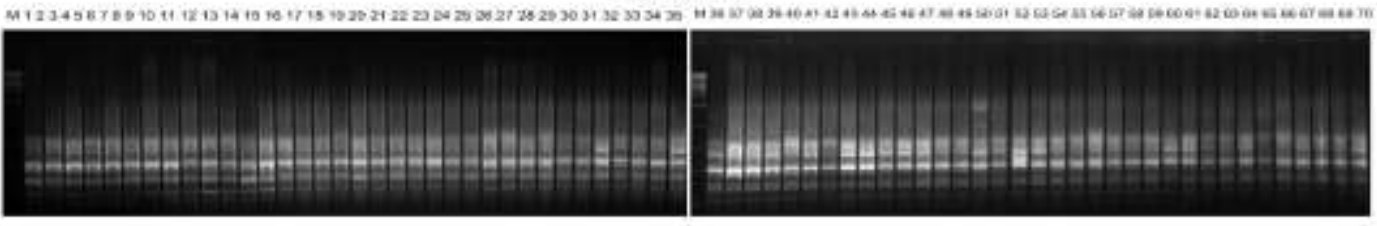

SCOT-4

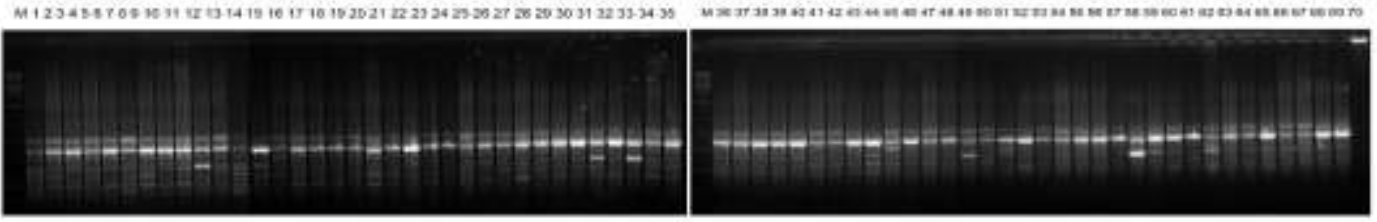

SSR-3

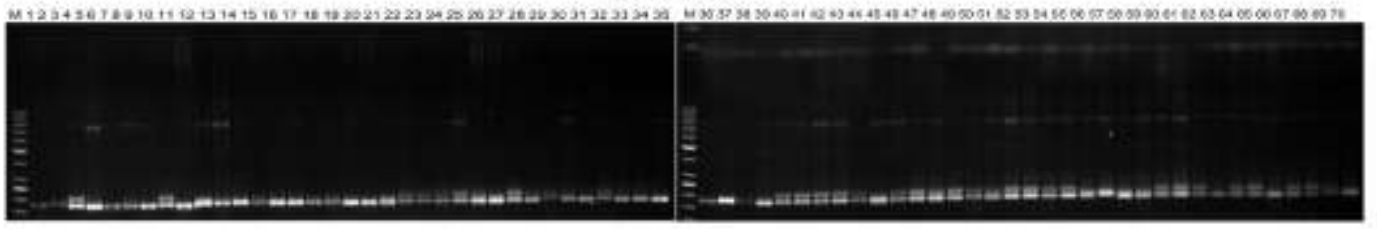

SSR-4

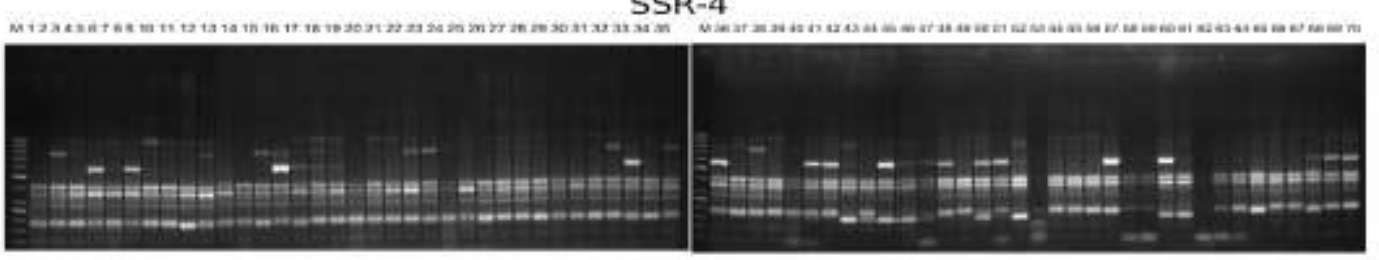

Fig. 1. Selected gel electrophoresis profiles of 70 wheat genotypes studied using SCoT and SSR PCR primers. 
Population structure and genome-wide association analysis for salinity tolerance in bread wheat using SNP, SSR and SCoT marker assays

Table 2. Sequences and primer name (PN) of DNA primers used for the SNP genotyping of wheat genotypes where targeted SNPs are surrounded by square brackets.

\begin{tabular}{|c|c|c|c|}
\hline PN & ce & PN & \\
\hline-86163814 & TTCTGTTAGGCATGC & BS00044237 & GGGTGTTCCTTTGT \\
\hline AX-86167869 & TCACTTGTCACTGCC[K]GTGCTCAAAGTCATC & BS00044720 & CTTAGTAGTTCACGT[A/G]CTCAGTAGCCCTGCA \\
\hline AX-94382081 & TTTGCGAAAGGGGCT[S]AAGCTAGTAGTTCGG & BS00046264 & CCATCGATCACCGGT[Y]GGCGCTACCAAAGGG \\
\hline AX-94392216 & TCCATTTGTACCTAA[K]CTGTGTAGTTGGTAA & BS00046963 & CCCGTCGCCGCCCGC[R]AGTCGCGGCTGAACC \\
\hline AX-94401211 & CACCTACAAGCTAAT[R]ATAAGGAAGCAGTTA & BS00049370 & GTATTTGTCCTTTTC[A/G]TCATTTGGGTCATTT \\
\hline AX-94406983 & АTCTTTACCACCTGG[S]CTTCTTGCTTTCTAT & BS00049818 & TGTATAGATACACTC[C/T]A] \\
\hline AX-94415898 & TAACACACACAGTTG[R]TGCTTAAACTGATTC & BS00050057 & GAACATCATCAACCT[K]GCAACCATTAATTCT \\
\hline AX-94431524 & GATAAGGTGCATGAA[R]GTCGTCTGATCTACT & BS00050109 & CAAAGAGAACTCTGC[Y]GGTCGATGTGTGATA \\
\hline AX-94442305 & GTCATCTAGTAAGGA[R]ACCAAATCACTCATC & BS00050993 & ACATTGTTGTGGGCT[M]TGTCCGAACTGATCA \\
\hline AX-94446956 & GGAATTGTGGGTCGA[K]CAAGAGATGGTTCGT & BS00057851 & CAATATCGTTGAGGA[Y]TTCCAAGTT \\
\hline AX-94454241 & GTTCTTGTGCTTGAG[Y]GTCTTAAGCAACCGC & BS00058591 & TGTACGTTCCCGCCT[Y]CCATGGACTACGGCG \\
\hline AX-94457966 & ATACACTGAGATTTC[Y]TGGAGATGTTGGTCG & BS00060686 & GCTCGGTGAGCAATT[K]ATGTTGG] \\
\hline AX-94486277 & TACAATGCATAGAAC[K]AGTGGTTATGTTGTG & BS00063425 & ACTGATAGGTAGATA[Y]GGTTGCCTCTTCAGT \\
\hline AX-94488939 & AGGCACTTCTT & BSOC & ACGGCCATTGCAGGT[R]CGGTTGGT \\
\hline AX-94527869 & CCTATAGGTACACTG & BS00064691 & ATCTGCTTCTCATCC[T/G]TG \\
\hline AX-94529943 & GCGATACACATGCCC[Y]GCCATCCGCGGATGA & 66143 & AGCCACAG \\
\hline AX-94540417 & TGTATTCTGTTCTGA & BSOC & TGACAAGGATTTATT[Y]AGT \\
\hline AX-94544363 & GAAGGAGGTGACCAG & BS00070903 & ACGATCTC \\
\hline AX-94545917 & CTGAAC & BSO0 & AGCAGAG \\
\hline AX-94558874 & CCAGCAGCTTCATTC[S]TCACCGGCCAGGTCA & BS00071558 & GACACTGT \\
\hline AX-94559367 & CCCTG & BS00073116 & TGAT \\
\hline BS00049977 & AAAGGAATTTCCTGG[Y]GTAGTACATTAGGAT & BSO & TTC \\
\hline BS00000006 & TCCCGC & BS00075815 & CGCA \\
\hline BS00018707 & AAGTCC & BS00076033 & TGAGCAG \\
\hline BS00021704 & TCAC & BSO & ACCA \\
\hline BS00021745 & CACGACAGAAGCAAC[R]CGTTTGCGAGGTTTG & BS00076248 & GACGGTAGGAATACG[R]CAGTTTCAGTCTTTT \\
\hline BS00022411 & ATCTA & BS00076622 & TCTC \\
\hline BS00022625 & TTTCTTTTTGTTGTG[R]GCTTGTTTCGTATGC & BS00077716 & GTTCATTCAGCACTA[Y]GAA \\
\hline BS00022653 & TGTAGT & BSO & TCTC \\
\hline BS00023673 & TTGCCGGCTGATGGA[Y]CTTAAAAGCGGCACT & BS00078124 & AGAGGATGCCGCTGA[Y]GCCGGAGAATTGTTG \\
\hline BS00024548 & ]CATGCCCC & BS00080749 & AGAAAACACACCCCC[A/C]GC \\
\hline BS00024786 & СTCCCCATTCAGTCC[Y]GACAAATGTAAATAT & BS00082503 & CAAGGGTATTACCCA[R]GCGTAACT \\
\hline BS00024921 & TCACAACAAGCGCA & $\mathrm{BSOC}$ & CGACCTGACTGCCAA[ \\
\hline BS00025017 & GAGCAGACTGTAGAG[C/T]TTTTACAATGGCAAG & BS00084133 & GAACATAGTTTTTGA[T/C]CTACGGGATGACAAG \\
\hline BS00030651 & TGACCGGACCCTGTA[Y]GCCGACGAGATTTTG & BS00089403 & ATCATGTGTATCATA[Y]GA \\
\hline BS00031140 & ACATACAGACCACTA[Y]TAAAACCAAAAATAC & BS00089597 & AGTTGAGAGAACAGC[T/C]ACGCATAATTCTCCG \\
\hline BS00031178 & TATGTTGTCTCCTTT[Y]CATTCATT & BS00089954 & CAACTCCCAGCTATC[R]TCGCCGGC \\
\hline BS00032039 & CCCGGTGATTTCACT[K]TAACATGAGTAAGGA & BS00097126 & GGAGCCTCCTTCGAA[T/C]GAACGTATTGTTACC \\
\hline BS00033795 & CAGCGCCGTCGCTTC[Y]AGGAGATCCAGCCCG & BS00100939 & TTACTCAAGGCATGG[Y]GGTTCGCGTCAAGGG \\
\hline 35234 & TAGTGC & BSO0 & GATGGAGAACCGTCC[M]GCTGCCAATACTTGT \\
\hline BS00037020 & ACAACCCCCATTGGA[K]AGGGATTTCTAAAGA & BS00104432 & TTTTGTAGCTCCTGA[M]TCGATGCAGCTTTAG \\
\hline 38820 & ACTGCCT[Y]G & BS00105878 & CTGATGCGTGTTGGG[Y]GGAAGAATAATCTCA \\
\hline BS00039211 & GAGCTAGTAGTGATG[T/C]ATTGGTCAGATCGAT & BS00106043 & AGGCCGAACCATCAG[Y]GGCTAATTAATTATT \\
\hline BSO & CTGCT & BSO & CA[Y]CATGTGTAATCTCGT \\
\hline BS00040798 & TGGATCGATGCGCTG[R]TGTTTACTGCA] & BS00107837 & ATGCATACAATACAT[R]CTTGCTGCAAATGAT \\
\hline BSO & CAACAACTTCATTCG[Y]CCGCTCGCTAC & BS00109036 & CTGAAGGAGGTGTAC[Y]GAATCCTTGCCCATG \\
\hline BS0004 & $\operatorname{ccc}$ & & \\
\hline
\end{tabular}


Table 3. The primer name (PN),total number of bands (TB), monomorphic bands count (MB), polymorphic bands count (PB) and polymorphism percentage as revealed by SCoT and SSR marker assays

\begin{tabular}{|c|c|c|c|c|}
\hline PN & TB & MB & PB & PP \\
\hline SCoT-01 & 9 & 1 & 8 & $89 \%$ \\
SCoT-02 & 6 & 0 & 6 & $100 \%$ \\
SCoT-03 & 5 & 1 & 4 & $80 \%$ \\
SCoT-04 & 7 & 1 & 6 & $86 \%$ \\
SCoT-05 & 10 & 3 & 7 & $7 \%$ \\
SCoT-10 & 9 & 1 & 8 & $89 \%$ \\
SSR-01 & 3 & 0 & 3 & $100 \%$ \\
SSR-02 & 2 & 2 & 0 & 0 \\
SSR-03 & 2 & 1 & 1 & $50 \%$ \\
SSR-04 & 6 & 2 & 4 & $67 \%$ \\
SSR-05 & 2 & 1 & 1 & $5 \%$ \\
\hline Total & $\mathbf{6 1}$ & $\mathbf{1 3}$ & $\mathbf{4 8}$ & $\mathbf{7 . 8 \%}$ \\
\hline
\end{tabular}

15 European countries or geo-graphic groups, were genotyped using 39 polymorphic SSR primers which, generated 635 PCR bands with a $72 \%$ of polymorphism, with a number of bands was ranged from 4 to 40 (Roussel et al 2005).

\section{Genetic diversity and population structure}

Analysis of population structure involves allocating each individual to a group in a population, and reporting the number of clusters. It has many applications in diversity studies including clustering of individuals, inferring demographic history of the population and identifying immigrants. There are many methods for inferencing population structure, such as the allele frequencies based analyses, Kinship analysis, and principal component analysis (PCA) (Lee et al 2009).

In this study, our aim is to identify the structure of the population of several accessions collected from different regional areas. We used the SSR, SCoT and SNP markers were used to compare between genetic structure and geographic origin (Figs. 2 and 3). Population structure analysis through STRUCTURE is widely conducted using Markov Chain Monte Carlo (MCMC), which uses genetic allele frequencies to allocate individuals of different groups (Pritchard et al., 2000). Analysis of the genetic structure using allele frequency of the Egyptian, Syrian and Iranian wheat accessions indicate that these accessions belong to a four different population groups. Where, for the most portion, Egyptian, Syrian and Iranian accessions were clustered depending on their country of origin. On the other hand, some accessions showed a type of genetic migration, which could be caused by varietal adaptation. Similar results were retrieved using the phylogenetic analysis (Fig. 3). Most accessions were almost clustered, depending on their geographical origin, although some Egyptian accessions were clustered with Iranian and Syrian accessions, which could indicate their source of origin. Such analysis could indicate a number of potential foreign accessions that could be successfully adapted in the Egyptian environment through local breeding programmes.

\section{GWAS analysis of wheat morpho-agronomic traits}

GWAS was emerged as a promising method for detecting important marker-trait associations based on the correlation between genotyping and agronomic data of several wheat accessions with low genetic relationships. GWAS has proven to be a useful tool for dissecting complex genetic mechanisms which regulate biotic stress in wheat (Liu et al 2018; Oyiga et al 2018).

SNP genotyping was used to detect genes that were related for wheat response to salinity stress. The statistical correlation between the 93 SNP markers and the seven agronomic traits of wheat was calculated (Table 4 and Fig. 4). GWAS analysis revealed 13 SNP markers. Which were distributed across the chromosomes of 7B (3), 6A (3), 5A (2), 2B (1), 2A (1), 5B (1), 3B (1), and 1B (1) (Table 4 and Fig. 4). Five different markers are correlated with STR trait (BS00064146, BS00101408, BS00089954, BS00000006, and BS00076622) (Table 4). The effect of these markers on STR trait was ranged from -0.56 (BS00076622) to 0.469 (BS00064146 and BS00101408). DF trait is correlated with four SNP markers (BS00024921, BS00083630, BS00078124, and BS00038820), where its effect was ranged from -2.544 (BS00078124) to 2.526 (BS00038820, and BS00024921). Some SNP markersshowed a correlation with multiple traits such as BS00038820 (DF and $\mathrm{PH}$ ), BS00107837 (NS and NT), and BS00089954 (NS and STR). 


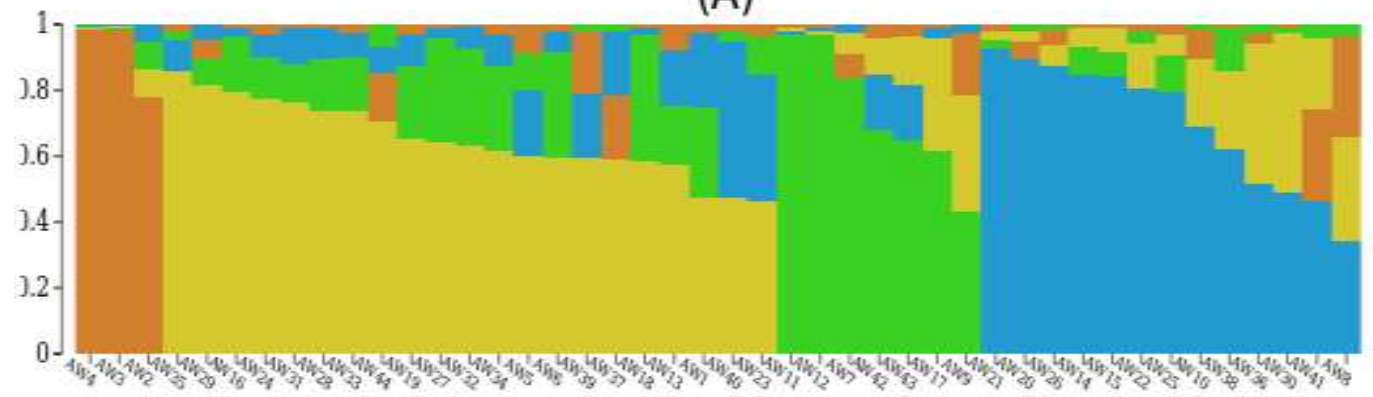

(B)

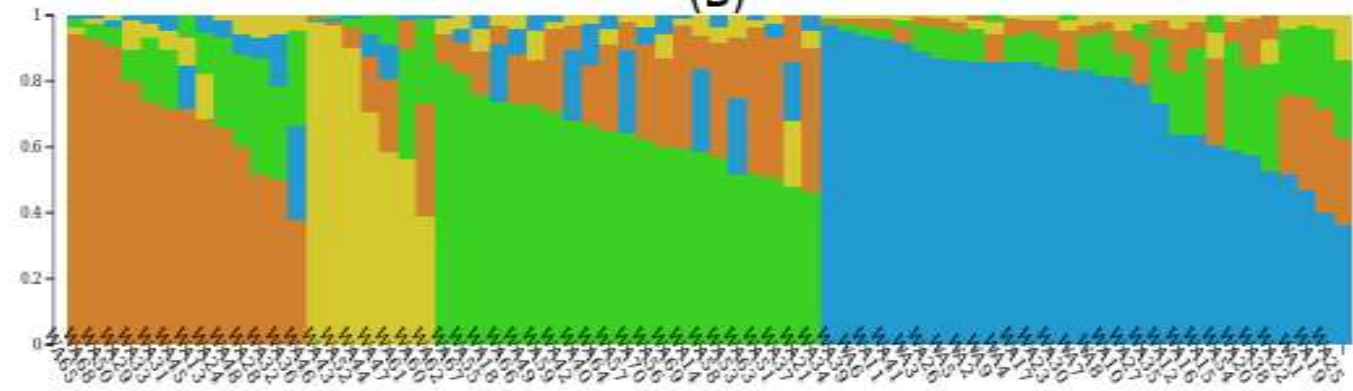

Fig. 2. Analysis of the population structure based on the allele frequencies using STRUCTURE software for the tested 70 wheat genotypes used in this study. (A) The population structure of the forty four accessions using SNP assay. (B) The seventy local and foreign genotypes structure using SCoT and SSR assays.

Table 4. The statistical effect and correlation significance (p.value) of the SNPs markers showing correlation with the agronomic traits of wheat under salinity stress

\begin{tabular}{|c|c|c|c|c|c|c|c|c|c|c|c|c|c|c|c|c|}
\hline \multicolumn{3}{|c|}{ SNP } & \multicolumn{2}{|c|}{ DF } & \multicolumn{2}{|c|}{ NS } & \multicolumn{2}{|c|}{ NSL } & \multicolumn{2}{|c|}{ NT } & \multicolumn{2}{|c|}{ PH } & \multicolumn{2}{|c|}{ SH } & \multicolumn{2}{|c|}{ STR } \\
\hline Name & Chr & Pos & $\begin{array}{c}\text { p. } \\
\text { value }\end{array}$ & effect & $\begin{array}{c}\text { p. } \\
\text { value }\end{array}$ & effect & $\begin{array}{c}\text { p. } \\
\text { value }\end{array}$ & effect & $\begin{array}{c}\text { p. } \\
\text { value }\end{array}$ & effect & $\begin{array}{c}\text { p. } \\
\text { value }\end{array}$ & $\begin{array}{c}\text { ef- } \\
\text { fect }\end{array}$ & $\begin{array}{c}\text { p. } \\
\text { value }\end{array}$ & $\begin{array}{c}\text { ef- } \\
\text { fect }\end{array}$ & \begin{tabular}{|c} 
p. \\
value
\end{tabular} & $\begin{array}{c}\text { ef- } \\
\text { fect }\end{array}$ \\
\hline BS00064146 & $7 \mathrm{~B}$ & 655818377 & 0.83 & -0.298 & 0.146 & 0.383 & 0.459 & 0.289 & 0.267 & 0.296 & 0.823 & 0.51 & 0.217 & 0.364 & $0.015^{\star}$ & 0.469 \\
\hline BS00101408 & $7 \mathrm{~B}$ & 657662487 & 0.83 & -0.298 & 0.146 & 0.383 & 0.459 & 0.289 & 0.267 & 0.296 & 0.823 & 0.51 & 0.217 & 0.364 & $0.015^{\star}$ & 0.469 \\
\hline BS00066143 & $5 A$ & 533072163 & 0.078 & $\mid-1.903$ & 0.131 & 0.326 & 0.057 & -0.578 & 0.122 & 0.339 & $0.03^{*}$ & -3.853 & 0.461 & -0.179 & 0.987 & -0.002 \\
\hline BS00024921 & $2 A$ & 733091124 & $0.021^{*}$ & 2.525 & 0.068 & -0.375 & 0.093 & 0.508 & 0.056 & -0.4 & 0.054 & 3.417 & 0.938 & -0.018 & 0.885 & -0.021 \\
\hline BS00089954 & $3 B$ & 543718628 & 0.583 & -0.578 & $0.045^{\star}$ & 0.43 & 0.994 & 0.002 & 0.104 & 0.351 & 0.451 & 1.299 & 0.66 & 0.105 & $0.037^{*}$ & 0.319 \\
\hline BS00107837 & $1 B$ & 674821632 & 0.403 & 1.071 & $0.025^{*}$ & -0.564 & 0.363 & 0.328 & $0.014^{*}$ & -0.638 & 0.229 & 2.533 & 0.69 & 0.109 & 0.6 & 0.091 \\
\hline BS00083630 & $6 \mathrm{~A}$ & 5604416 & $0.02^{*}$ & -2.372 & 0.852 & 0.035 & 0.075 & -0.503 & 0.997 & -0.001 & 0.145 & -2.384 & 0.352 & -0.196 & 0.804 & 0.033 \\
\hline BS00000006 & $5 \mathrm{~A}$ & 706240365 & 0.931 & -0.083 & 0.913 & 0.02 & 0.799 & -0.068 & 0.81 & 0.045 & 0.544 & -0.951 & 0.363 & -0.189 & $0.044^{*}$ & -0.269 \\
\hline BS00078124 & $6 \mathrm{~A}$ & 617182750 & $0.036^{*}$ & -2.544 & 0.375 & 0.197 & 0.714 & 0.122 & 0.34 & 0.217 & 0.126 & -3.001 & 0.368 & 0.223 & 0.738 & -0.053 \\
\hline BS00021704 & $6 \mathrm{~A}$ & 611851563 & 0.089 & 2.055 & 0.271 & -0.261 & 0.557 & -0.196 & 0.267 & -0.267 & 0.102 & 3.229 & $0.032^{*}$ & -0.593 & 0.102 & -0.278 \\
\hline BS00050057 & $5 B$ & 658370171 & 0.568 & 0.7 & 0.843 & -0.053 & 0.057 & 0.67 & 0.808 & -0.064 & 0.377 & 1.768 & $0.022^{*}$ & 0.733 & 0.964 & -0.008 \\
\hline BS00076622 & $7 \mathrm{~B}$ & 717202678 & 0.639 & -0.733 & 0.781 & 0.095 & 0.594 & -0.234 & 0.783 & 0.094 & 0.941 & 0.188 & 0.26 & -0.448 & $0.024^{*}$ & -0.561 \\
\hline BS00038820 & $2 B$ & 64988240 & $0.047^{*}$ & 2.526 & 0.598 & 0.139 & 0.379 & 0.308 & 0.532 & 0.166 & $0.045^{*}$ & 4.161 & 0.297 & 0.317 & 0.531 & 0.117 \\
\hline
\end{tabular}

AUJASCI, Arab Univ. J. Agric. Sci., 28(3), 2020 


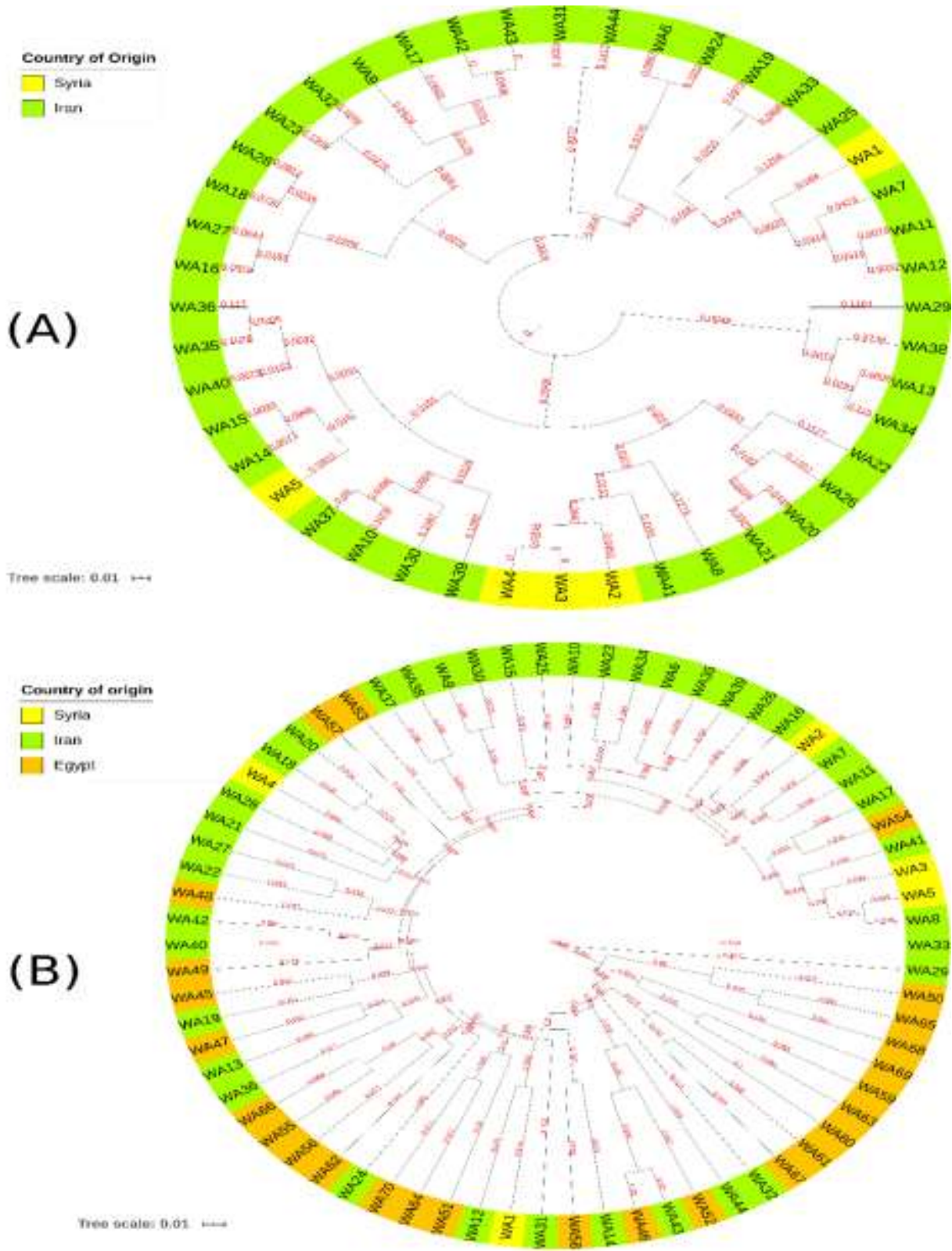

Fig. 3. The phylogenetic diversity for the tested wheat genotypes used in this study. (A) The phylogenetic tree using SNP genotyping assay for the forty four foreign accessions. (B) The phylogenetic tree of the severity local and foreign genotypes using SCOT and SSR assays 


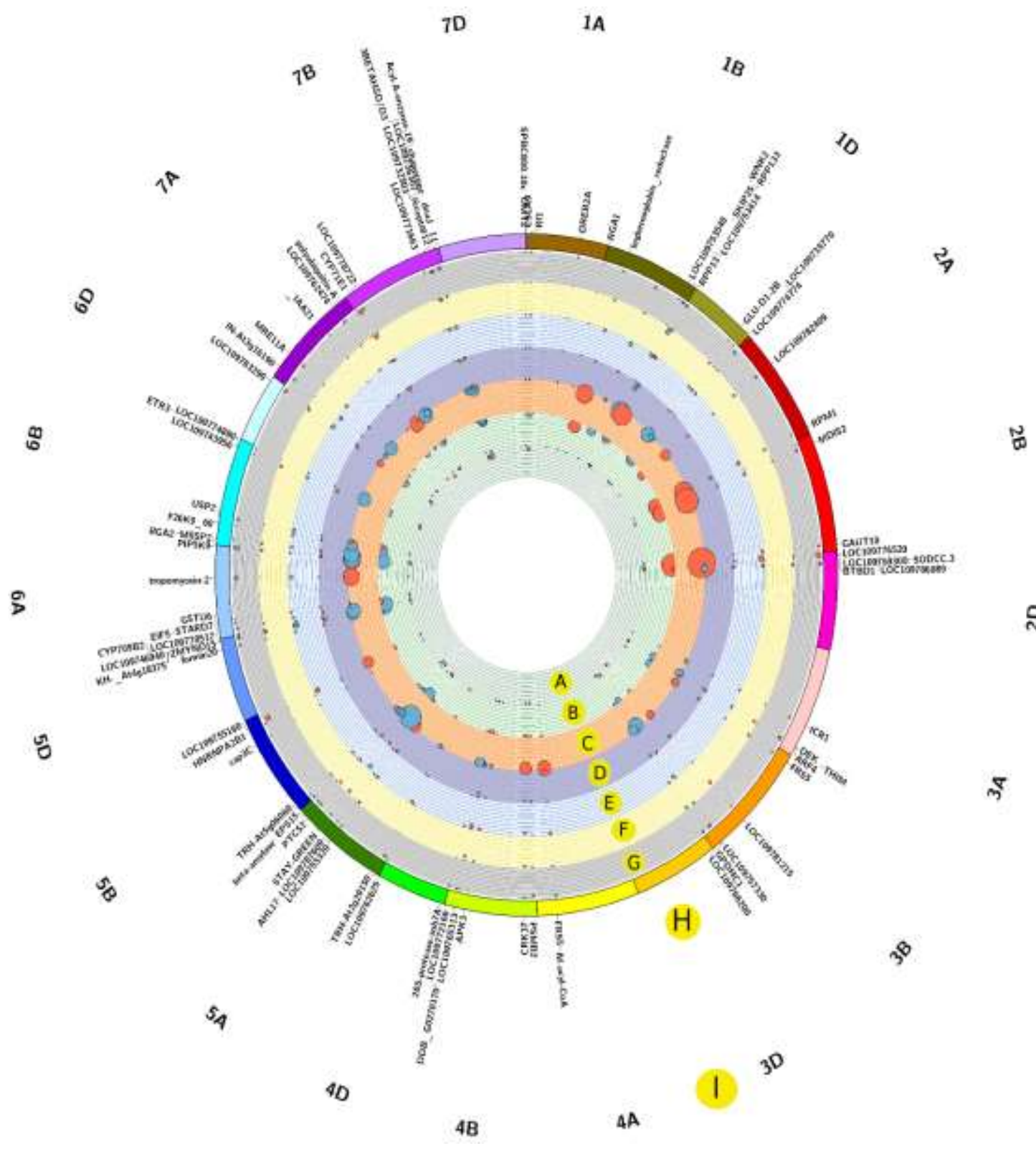

Fig. 4. The genomic distribution and GWAS analysis of the studied SNP markers. The significance value and statistical effect regarding SNP marker and their correlation with STR (A), DF (B), PH (C), NT (D), NSL $(E), N S(F), S H(G)$ traits. The size and color of the circles indicate the p.value and effect markers. (H) Genes near these markers are shown by their chromosome location on the wheat genome (I). 
By studying genes located near the SNP markers associated with wheat agronomic traits under salinity, 13 different genes were identified (Table 5). These genes included CYP709B2, which has been reported to be highly associated with salinity tolerance in Arabidopsis thaliana. It has been concluded that plants with mutant CYP709b3 may be sensitive to ABA and salt stress during germination (Mao et al. 2013). Additionally, an association with BS00038820 marker was detected, which is located near MDIS2 gene and associated with DF and $\mathrm{PH}$ traits. The MDIS2 gene is highly correlated with root hair morphogenesis, which is extremely important process in the response of plants to salinity. Such associations have been detected in chickpea (Kaashyap et al 2018) and soybean (Duzan et al 2004). The significant association between STAYGREEN gene and $\mathrm{PH}$ trait under salinity stress is not surprising (Table 5). Recently, it has been reported that the STAY-GREEN gene that encodes chlorophyll-degrading $\mathrm{Mg}++-$ dechelatase is essential for the regulation of lifespan and yield in rice cultivars (Shin et al 2020). The PIP5K9 gene has showed a significant association with $\mathrm{SH}$ trait (Table 5). This indicated a relationship between PIP5K9 gene and wheat salinity tolerance which could be due to the importance of polyamines in stress reactions, such as drought, salinity and heat stresses, where PIP5K9 gene is required for polyamine-triggered $\mathrm{K}+$ efflux in plant roots (Zarza et al 2020). As shown in Table 5, MSSP2 gene is genetically near to BS00078124, which is correlated with DF trait (Table 4). A significant expression of MSSP2 transport protein was reported in the phosphoproteome analysis during the study of defense mechanisms for wheat against drought stress (Zhang et al 2014). A beta-amylase-related wheat gene was detected that correlated with STR trait during salinity stress (Table 5). It has been reported that beta-amylases are stress-induced proteins that is related to light- and stress-dependent enhancement of amylolytic activities in barley (Dreier et al 1995). The promotion of wheat seed germination under salt stress could be increased by beta-amylase activity (Duan et al 2007). The association between disease resistance genes and plant response to salinity stress has been recognized in different plant species (Zhang et al 2018). GWAS analysis revealed a significant association with BS00024921, which is associated with DF trait and is located near the RPM1 gene, which is a disease resistance gene that regulates a sustained increase in cytosolic calcium that is essential for oxidative bursting and hypersensitive cell death (Grant et al 2000).

Table 5. List of genes located in the vicinity of trait-associated SNPs markers.

\begin{tabular}{|c|l|c|}
\hline Marker & Gene full name & Gene abbreviation \\
\hline BS00083630 & cytochrome P450 709B2 & CYP709B2 \\
BS00038820 & MALE DISCOVERER 2 & MDIS2 \\
BS00066143 & STAY-GREEN & STAY-GREEN \\
BS00089954 & LOC109781215 & - \\
BS00021704 & phosphatidylinositol 4-phosphate 5-kinase 9 & PIP5K9 \\
BS00078124 & monosaccharide-sensing 2 & MSSP2 \\
BS00064146 & LOC109732503 & - \\
BS00101408 & LOC109736307 & - \\
BS00050057 & LOC109755160 & - \\
BS00107837 & LOC109753414 & - \\
BS00000006 & beta-amylase & - \\
BS00076622 & 3beta-hydroxysteroid-dehydrogenase/decarboxylase & 3BETAHSD/D3 \\
BS00024921 & disease resistance RPM1 & RPM1 \\
\hline
\end{tabular}




\section{CONCLUSION}

The genetic diversity and population structure of a set of local and international wheat accessions were investigated. These accessions were successfully assigned to different groups depending on their genetic background. This study revealed the genetic structure of adapted and imported wheat accessions, which could be used to select potential wheat accessions for local breeding programs. In addition, GWAS analysis was used to identify some genes that are related to wheat resistance to salinity stress. Molecular markers that could be used to select salinity-tolerant accessions could be integrated into national genetic improvement programs. The SNP genotyping assay is a very potential technology that could be efficiently applied to detect some genes that control wheat response to salinity stress.

\section{REFERENCES}

Abbasabad E.Z., Mohammadi S.A., Moghaddam M. and Kamali M.R.J. (2017). Analysis of genetic diversity, population structure and linkage disequilibrium in Iranian wheat landraces using SSR markers. Plant Genet. Resour. 15, 327.

Abdein M.A., El-Moneim D.A., Taha S.S., ALJuhani W.S.M. and Mohamed S.E. (2018). Molecular characterization and genetic relationships among some tomato genotypes as revealed by ISSR and SCoT markers. Egypt. J. Genet. Cytol. 47 p.

Abdel-Lateif K.S. and Hewedy O.A., others (2018). Genetic diversity among Egyptian wheat cultivars using SCOT and ISSR markers. SABRAO J. Breed Genet 50, 36-45.

Alexandratos N. and Bruinsma J. (2012). World agriculture towards 2030/2050: the 2012 revision.

Aliyu R., Adamu A.K., Muazu S., Alonge S.O. and Gregorio G.B. (2011). Tagging and validation of SSR markers to salinity tolerance QTLs in rice (Oryza spp), in: 2010 International Conference on Biology, Environment and Chemistry, IPCBEE, IACSIT Press, Singapore. pp. 328-332.

Alsamman A.M., Adawy S.S., Ibrahim S.D., Hussein B.A. and Hussein E.H.A., others, (2017). Selective Amplification of Start codon Polymorphic Loci (SASPL): a new PCR-based molecular marker in olive. Plant Omics 10, 64.
Altschul S.F., Madden T.L., Schäffer A.A., Zhang J., Zhang Z., Miller W. and Lipman D.J. (1997). Gapped BLAST and PSI-BLAST: a new generation of protein database search programs. Nucleic Acids Res. 25, 3389-3402.

Aryan R.K., Singh A.K., Mishra S.R., Chaudhari R., Katiyar P., Kumar N. and Nishad A. (2018). Importance of under variable moisture regimes on wheat (Triticum aestivum L.) cultivars. J. Pharmacogn. Phytochem. 7, 1533-1535.

Awan Z. (2019). Plant Molecular Biology Databases. Highlights Biosci. pp. 1-7.

https://doi.org/10.36462/H.BioSci.20191

Ballesta P., Mora F. and Del Pozo A. (2020). Association mapping of drought tolerance indices in wheat: QTL-rich regions on chromosome 4A. Sci. Agric. 77 p.

Collard B.C.Y. and Mackill D.J. (2009). Start codon targeted (SCoT) polymorphism: a simple, novel DNA marker technique for generating gene-targeted markers in plants. Plant Mol. Biol. Report. 27, 86.

Consortium I.W.G.S., others (2014). A chromosome-based draft sequence of the hexaploid bread wheat (Triticum aestivum) genome. Science 80, 345.

Dreier W., Schnarrenberger C. and Börner T. (1995). Light-and stress-dependent enhancement of amylolytic activities in white and green barley leaves: $\$ \beta \$$-amylases are stress-induced proteins. J. Plant Physiol. 145, 342-348.

Duan P., Ding F., Wang F. and Wang B.S. (2007). Priming of seeds with nitric oxide donor sodium nitroprusside (SNP) alleviates the inhibition on wheat seed germination by salt stress. J. Plant Physiol. Mol. Biol. 33, 244.

Duzan H.M., Zhou X., Souleimanov A. and Smith D.L. (2004). Perception of Bradyrhizobium japonicum Nod factor by soybean [Glycine max (L.) Merr.] root hairs under abiotic stress conditions. J. Exp. Bot. 55, 2641-2646.

Etminan A., Pour-Aboughadareh A., Mohammadi R., Ahmadi-Rad A., Noori A., Mahdavian Z. and Moradi Z. (2016). Applicability of start codon targeted (SCoT) and inter-simple sequence repeat (ISSR) markers for genetic diversity analysis in durum wheat genotypes. Biotechnol. Biotechnol. Equip. 30, 1075-1081. 
FAOSTAT F. (2018). Agriculture Organization of the United Nations Statistics Division. Economic and Social Development Department, Rome, Italy. Available online: http://faostat3. fao. org/home/E (accessed on August 2018).

Faris J.D. (2014). Wheat domestication: Key to agricultural revolutions past and future, in: Genomics of Plant Genetic Resources. Springer, pp. 439-464.

Girish K. and Dubey S. (2018). Eukaryotic Molecular Biology Databases: An Overview. Highlights Biosci. 1, 1-7.

Grant M., Brown I., Adams S., Knight M., Ainslie A. and Mansfield J. (2000). The RPM1 plant disease resistance gene facilitates a rapid and sustained increase in cytosolic calcium that is necessary for the oxidative burst and hypersensitive cell death. Plant J. 23, 441-450.

Hassan A.H., El-Heba G.A. and Mohamed A., others, (2020). DNA Variations between Medicago truncatula Symbiotic Mutant Line and $\mathrm{Na}$ tive Variant Using Fluorescence-Based AFLP Marker. Highlights Biosci. 3, 1-5.

Heidari P., Etminan A., Azizinezhad R. and Khosroshahli M. (2017). Genomic variation studies in durum wheat (Triticum turgidum ssp. durum) using CBDP, SCOT and ISSR markers. Indian J Genet PI Br 77, 379-386.

Hussain B., Lucas S.J., Ozturk L. and Budak, H., (2017). Mapping QTLs conferring salt tolerance and micronutrient concentrations at seedling stagein wheat. Sci. Rep. 7, 1-14.

Ibrahim S.D., Adawy S.S., Atia M.A.M., Alsamman A.M. and Mokhtar M.M. others, (2016). Genetic diversity, variety identification and gene detection in some Egyptian grape varieties by SSR and SCoT markers. Plant Omics 9, 311.

Kaashyap M., Ford R., Kudapa H., Jain M., Edwards D., Varshney R. and Mantri N. (2018). Differential regulation of genes involved in root morphogenesis and cell wall modification is associated with salinity tolerance in chickpea. Sci. Rep. 8, 4855.

Krzywinski M., Schein J., Birol, Inanç, Connors J., Gascoyne R., Horsman D., Jones S.J. and Marra M.A. (2009). Circos: an information aesthetic for comparative genomics. Genome Res. 19, 1639-1645.

Lee C., Abdool A. and Huang C.H. (2009). PCAbased population structure inference with generic clustering algorithms. BMC Bioinformatics $10, \mathbf{S 7 3 .}$
Lipka A.E., Tian F., Wang Q., Peiffer J., Li M., Bradbury P.J., Gore M.A., Buckler E.S. and Zhang Z. (2012). GAPIT: genome association and prediction integrated tool. Bioinformatics 28, 2397-2399.

Liu Ying, Liu, Yanyan, Zhang Q., Fu B., Cai J., Wu J. and Chen Y. (2018). Genome-wide association analysis of quantitative trait loci for salinity-tolerance related morphological indices in bread wheat. Euphytica 214, 176.

Mao G., Seebeck, T., Schrenker D. and Yu O. (2013). CYP709B3, a cytochrome P450 monooxygenase gene involved in salt tolerance in Arabidopsis thaliana. BMC Plant Biol. 13, 169.

Nahas L.D., Alsamman A.M., Hamwieh A., Al-Husein N. and Lababidi G. (2020). Characterization of EST-SSR markers in bread wheat EST related to drought tolerance and functional analysis of SSR-containing unigenes. Highlights Biosci. 3, 1-12.

Nassar A.E., Mousa K.H., Madbouly A.A., Ibrahim S.D. and Alsamman A.M. (2018). Identification of genes for wheat fungal resistance using bioinformatics techniques. Highlights Biosci 1, 1-10.

Oyiga B.C., Sharma R.C., Baum M., Ogbonnaya F.C., Léon J. and Ballvora A. (2018). Allelic variations and differential expressions detected at quantitative trait loci for salt stress tolerance in wheat. Plant. Cell Environ. 41, 919-935.

Perez-Lara E., Semagn K., Tran V.A., Ciechanowska I., Chen H., Iqbal M., N'Diaye A., Pozniak C., Strelkov S.E. and Hucl P.J., others, (2017). Population structure and genomewide association analysis of resistance to disease and insensitivity to Ptr toxins in Canadian spring wheat using 90K SNP array. Crop Sci. 57, 1522-1539.

Pritchard J.K., Stephens M. and Donnelly P. (2000). Inference of population structure using multilocus genotype data. Genetics 155, 945959.

Qadir M., Sultan A., Khan H., Khan A.S., Kazi A.M. and Basra S.M.A. (2014). Identification of QTLs for drought tolerance traits on wheat chromosome 2A using association mapping. Int. J. Agric. Biol. $16 \mathrm{p}$.

Rafalski A. (2002). Applications of single nucleotide polymorphisms in crop genetics. Curr. Opin. Plant Biol. 5, 94-100.

Rogers S.O. and Bendich A.J. (1989). Extraction of DNA from plant tissues, in: Plant Molecular Biology Manual. Springer, pp. 73-83. 
Roussel V., Leisova L., Exbrayat F., Stehno Z. and Balfourier F. (2005). SSR allelic diversity changes in 480 European bread wheat varieties released from 1840 to 2000. Theor. Appl. Genet. 111, 162-170.

Shin D., Lee S., Kim T.H., Lee J.H., Park J., Lee J., Lee J.Y., Cho L.H., Choi J.Y., Lee W. others, (2020). Natural variations at the StayGreen gene promoter control lifespan and yield in rice cultivars. Nat. Commun. 11, 1-11.

Sparks D.L., Page A.L., Helmke P.A. and Loeppert R.H. (2020). Methods of soil analysis, part 3: Chemical methods. John Wiley \& Sons.

Turki N., Shehzad T., Harrabi M. and Okuno K. (2015). Detection of QTLs associated with salinity tolerance in durum wheat based on association analysis. Euphytica 201, 29-41.

Vivod'ik M., Balážová Ž., Gálová Z. and Petrovičová L. (2017). Genetic Diversity Analysis Of Maize (Zea mays L.) Using SCoT Markers. J. Microbiol. Biotechnol. Food Sci. 6, 1170.

Wu X., Chang X. and Jing R. (2012). Genetic insight into yield-associated traits of wheat grown in multiple rain-fed environments. PLoS One 7.

Würschum T., Langer S.M., Longin C.F.H., Korzun V., Akhunov E., Ebmeyer E., Schachschneider R., Schacht J., Kazman E. and Reif J.C. (2013). Population structure, genetic diversity and linkage disequilibrium in elite winter wheat assessed with SNP and SSR markers. Theor. Appl. Genet. 126, 1477-1486.

Zaimah N.S. (2019). Plant resistance gene, SNP and genome annotation an overview. Highlights Biosci. 2, 1-6.

Zarza X., Van Wijk R., Shabala L., Hunkeler A., Lefebvre M., Rodriguez-Villalón A., Shabala S., Tiburcio A.F., Heilmann I. and Munnik T. (2020). Lipid kinases PIP5K7 and PIP5K9 are required for polyamine-triggered $\mathrm{K}+$ efflux in Arabidopsis roots. Plant J. https://doi.org/doi.org/10.1111/tpj.14932

Zhang M., Lv D., Ge P., Bian Y., Chen G., Zhu G., Li X. and Yan Y. (2014). Phosphoproteome analysis reveals new drought response and defense mechanisms of seedling leaves in bread wheat (Triticum aestivum L.). J. Proteomics 109, 290-308.

Zhang Y., Chao C., Shi Z., Cheng H., Jie B., Zheng C., Li H., Zhang G., others, (2018). Identification of salinity-related genes in ENO2 mutant (eno2-) of Arabidopsis thaliana. J. Integr. Agric. 17, 94-110. 


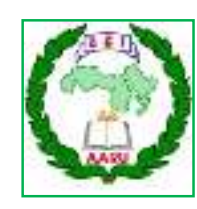

مجلة اتحاد الجامعات العربية للعلوم الزراعية، جامعة عين شمس، القاهرة، مصر مجلد(28)، عدد(3)، 884-871، 2020

تحليل التركيب العثيري والارتباط على مستوى الجينوم لتحمل الملوحة في قمح الخبز

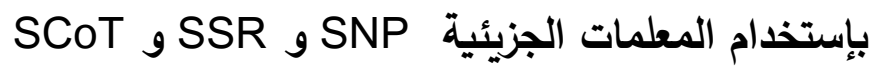

السمان محمود السمان 1" - شفيق درويش ابراهيم1 - محمد عبدالسلام رالشد² - أيمن حنفي عبد العظيم عطا2-

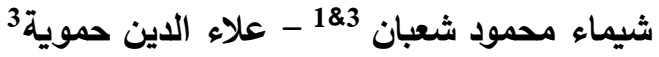

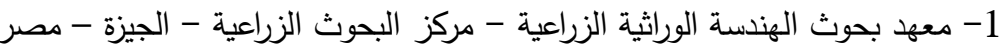

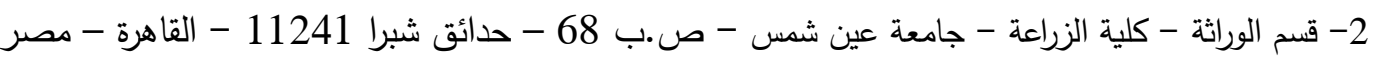

3- ايكاردا - المركز الدولى للبحوث الزراعية فى المناطق الجافة - الجيزة - مصر

*Corresponding author: smahmoud@ageri.sci.eg

Accepted 25 September, 2020

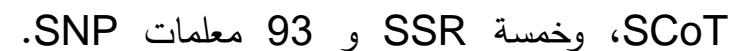
أظهر تحليل التركيبة العشيرية بإستخدام تردد الأليل

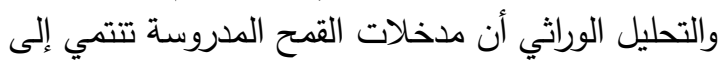

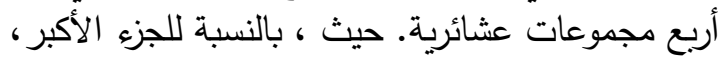

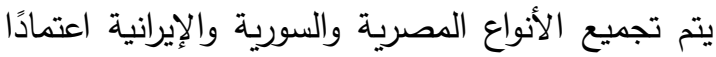

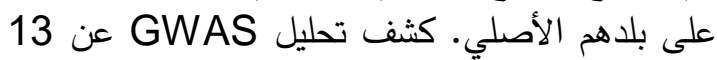

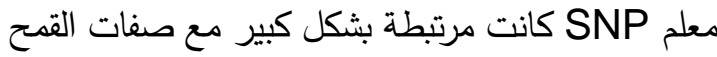

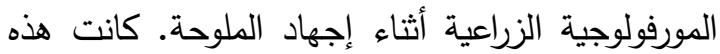

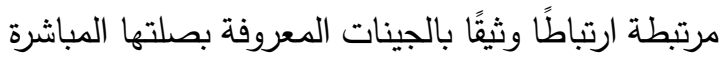

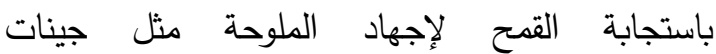
STAY-GREEN , 2MDIS, 2CYP709B 2MSSP و 9PIP5K ,

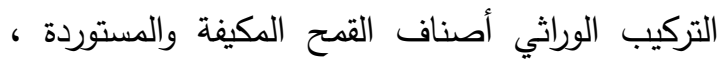

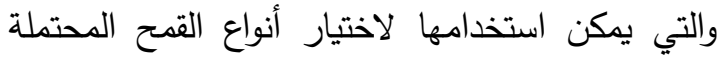

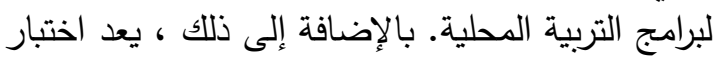

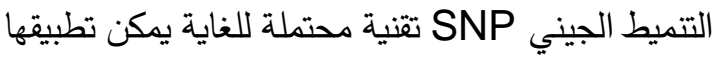

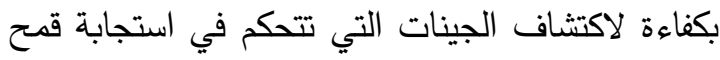

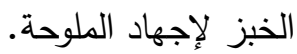

القحح هو غذاء ثابت وأساسي في دول العالم النامي،

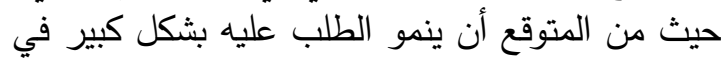

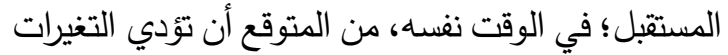

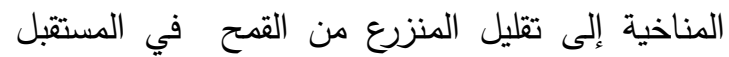

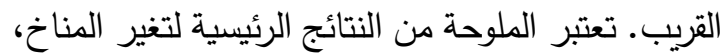

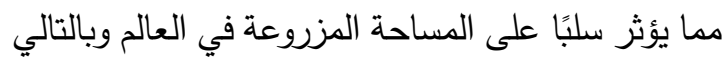
يؤثر على إنتاج القمح العالمي. أهدافنا في هذه الدئ الدراسة

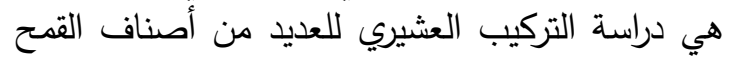
الدصرية والدولية وتحديد العوامل الوراثية التي تتحكم في التئي

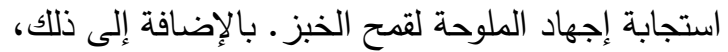

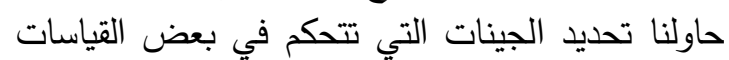

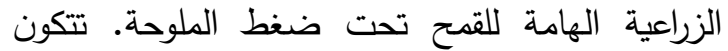

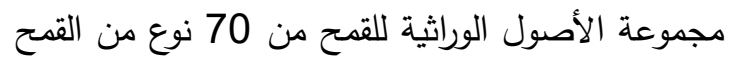

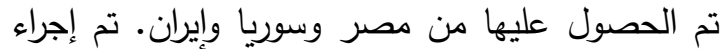
تقييم تحمل الملوحة على مدار عامي 2018 و 2019 تصني 2019 في الحقل وفي الصوبة. تم إجراء تحليل ارتباط الجينوم وتحليل البنية العشيرية بإستخدام ستة العتبة (GWAS) 